\title{
Update on the Management of Urological Problems Following Kidney Transplantation
}

\author{
Mehmet Sarier ${ }^{a} \quad$ Ozlem Yayar ${ }^{b} \quad$ Asuman Yavuz ${ }^{b} \quad$ Hasan Turgut $^{c} \quad$ Erdal Kukuld

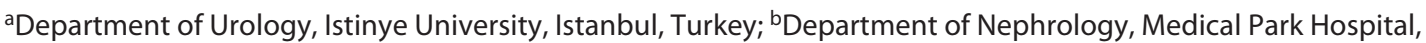

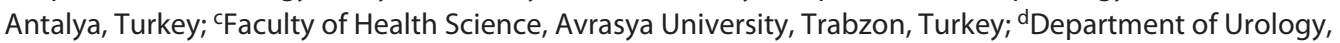 \\ Medical Park Hospital, Antalya, Turkey
}

\section{Keywords}

Kidney transplantation · Vesicoureteral reflex · Urological complications · Allograft lithiasis · Benign prostatic hyperplasia

\begin{abstract}
Urological problems in kidney transplant recipients are not limited only to posttransplantation urological complications. These problems are a cause of significant patient mortality and morbidity that have wide-ranging effects on graft survival throughout the entire life of the graft. Ultimately, the transplant comprises a major portion of the urinary system; therefore, the transplant team should be prepared for foreseeable and unforeseeable urological problems in the short and long terms. These mainly include postoperative urological complications (urine leakage, ureteral stenosis, and vesicoureteral reflux), bladder outlet obstruction, and graft urolithiasis. In recent years, significant advances have been made in the management of urological complications, especially due to advances in endourologic interventions. The aim of this review is to summarize the management of urological problems after kidney transplantation in the context of the current literature.

(c) 2021 S. Karger AG, Basel
\end{abstract}

\section{Introduction}

At present, kidney transplantation is undeniably the better option for the treatment of ESRD compared to dialysis. The 5-year survival rate with kidney transplantation, regardless of whether the donor is living or deceased, is more than twice that of dialysis, while dialysis costs 3 times more [1]. Due to the longer survival and better quality of life it provides, more kidney transplants are being performed daily around the world. It must be borne in mind that kidney transplantation is a surgical operation and, like any surgical operation, can cause complications. Under the current well-defined standards, advanced surgical techniques and the development of immunosuppressive drugs have reduced rates of posttransplant morbidity and graft loss to an all-time low. Urological complications represent the largest proportion of operative complications, occurring at rates of 1-15\% after transplantation [2-4]. However, definitions vary and hence an accurate estimation of the incidence is difficult. Furthermore, urological problems are not limited to postoperative urological complications, and these problems are known to impact graft survival and comprise a significant cause of patient morbidity and mortal- karger@karger.com

(C) 2021 S. Karger AG, Basel

www.karger.com/uin

Karger!
Mehmet Sarier

Department of Urology, Medical Park Hospital

Tekelioglu St., No. 7, Muratpaşa

Antalya 07110 (Turkey)

drsarier@gmail.com 
ity. An analysis of the literature shows that the main focus when describing urological disorders following transplantation has been on postoperative urological complications such as urine leakage, ureteral stenosis, and vesicoureteral reflux (VUR). Therefore, while planning this review, we deemed it necessary to discuss posttransplant urological disorders from a broader perspective. The aim of this review is to summarize the management of postkidney transplantation urological problems in the context of the current literature.

\section{Postoperative Urological Complications}

Early postoperative urological complications are those most responsible for prolonged hospital length of stay. Predictors of urological complications include older donor age and recipient history of cardiac events [5]. Other independent risk factors include long dialysis time and low bladder capacity [6]. However, the relationship between living donor or deceased donor transplants and urological complications is unclear. Routine intraoperative ureteral stenting has been shown to significantly lower the rate of urological complications [7, 8]. Ureteral stents can be placed intraoperatively in the form of an internal double-J stent or as an external (percutaneous) stent. The advantage of the widely used internal double-J stent is that the lower postoperative urological complications occur less frequently [9]. However, there is no consensus regarding the dwell time of internal double-J stents. The goal is to remove the double-J stent within an optimal timeframe to avoid the risk of stent-related complications such as urinary tract infection (UTI) [10]. At the same time, this period must be long enough for complete healing of the ureterovesical anastomosis. When recent studies and meta-analyses are examined, a dwell time of about 3 weeks emerges as most suitable $[11,12]$.

\section{Ureteral Stenosis}

With an incidence of between 2 and 13\% in different series, ureteral stenosis is one of the most common major urological complications following transplantation [1315]. It may occur in the early ( $<3$ months) or late $(>3$ months) postoperative period. It is primarily attributed to poor surgical technique and ureteral devascularization. Ureteral stenosis often manifests in the early period as ureteral obstruction. During this period, the etiology may involve ureteral intraluminal factors such as thrombus; edema and kinking of the anastomosis line; and extraluminal factors such as the pressure exerted by hematoma or lym- phocele [16]. In the late period, it manifests with ureteral stricture, which involves narrowing or obstruction of the ureteral lumen due to primary scarring or fibrosis of the ureter, with no external compression. Ischemic necrosis is the main etiological factor in ureteral stricture. This ischemia most often occurs due to devascularization or BK polyomavirus infection [17]. Ureteral stricture can occur in any part of the ureter, but is most frequently seen in the ureterovesical anastomosis. For this reason, endourologic approaches are usually sufficient for its treatment. These include balloon dilation, ureterovesical junction resection, double-J stenting, metallic stenting, and endoureterotomy $[13,18]$. Kwong et al. [19] showed in a systematic review that balloon dilation was the most frequently used endourologic approach and its success rate was $58.6 \%$. For patients who do not respond to minimally invasive methods and have stenosis lasting for $>3$ months, the implantation of self-expanding metallic ureteral stents is a safe and effective treatment with low morbidity and associated complications $[18,20]$. Surgical ureter reimplantation is necessary in patients for whom minimally invasive approaches do not yield satisfactory results.

\section{Urine Leakage}

Urine leakage is the most common early postoperative urological complication, with an incidence rate between 1.5 and $8.9 \%[2,21]$. It is usually a result of ischemic necrosis of the distal ureteral segment of the ureterovesical anastomosis. For this reason, it is important to prevent ureteral devascularization after graft nephrectomy and ensure that a watertight ureterovesical anastomosis is created. Minimally invasive procedures should be considered first for the treatment of urine leakage. These include urethral catheterization, percutaneous nephrostomy, and antegrade or retrograde double-J stent placement. Urethral catheterization should be the primary approach. This allows the correction of minor leaks associated with delayed healing. In addition, ureteric stenting and percutaneous nephrostomy with urethral catheterization can offer a potential definitive management option with close surveillance of graft function. The goal of treatment should be to ensure maximum decompression of the urinary tract. Patients must be followed closely after the removal of a double-J stent due to the risk of developing secondary ureteral stricture [22], which reduces the longterm success of endourologic treatments to approximately $60 \%$ [23]. If endourologic interventions are not effective, open surgical approaches such as ureteral reimplantation or pyeloureterostomy with the native ureter should be considered [24]. 
Vesicoureteral Reflux

VUR occurs after kidney transplantation in $2-79 \%$ of the cases [25]. Today, the most commonly used ureteroneocystostomy (UNC) technique in transplant surgery is the Lich-Gregoir technique with an extravesical approach. It is well known in urology practice that creating an adequate submucosal tunnel during UNC is essential to prevent VUR. However, the creation of a large anastomosis to avoid ureteral stenosis, especially using the extravesical technique, increases the incidence of VUR [26]. VUR is the most common postoperative urological complication in pediatric kidney transplant recipients [27] and can cause serious morbidity when accompanied by lower urinary tract symptoms (LUTSs). VUR is usually asymptomatic in adults. It should be kept in mind that while the role of urological disorders is up to $60 \%$ in the etiology of ESRD in children, this rate is between 1.4 and $5 \%$ in adults $[28,29]$. There is lingering uncertainty regarding the impact of VUR in early and late graft function and graft survival. Studies published about 2 decades ago implicated VUR as a major factor in late renal graft failure [30]. In contrast, no correlation between VUR and early bacteriuria, renal function, or graft survival was observed in a recent series of 1,008 patients [31]. Unlike urine leakage and ureteral stenosis, treatment for VUR is required in the longer term following transplantation. Treatment is essential in symptomatic VUR patients with recurrent UTI and/or reflux nephropathy.

Endoscopic treatment with submucosal Teflon injection (Sting) is widely used for the treatment of VUR because it is easily performed and is associated with low morbidity. Success rates are between 54 and $74 \%$ overall and can reach up to $90 \%$ in patients with low-grade VUR [16]. The procedure can also be repeated in patients who do not show improvement after a single session. Alternatively, treating VUR by open surgery with ureteral reimplantation offers success rates of $83-100 \%$ [29]. In brief, the Sting procedure should be the first choice for lowgrade symptomatic VUR, for which it has high success rates, while open surgery should be considered for patients with high-grade VUR.

\section{Bladder Outlet Obstruction}

Urinary retention due to bladder outlet obstruction (BOO) is an important urological problem that can occur in both the early and late periods after kidney transplantation, particularly in middle-aged and older men. BOO can occur due to bladder neck obstruction or benign

Urological Problems Following Kidney

Transplantation prostatic hyperplasia (BPH). Gratzke et al. [32] reported that dialysis duration $>120$ months and age over 60 years were associated with significantly higher risk of urinary retention.

Early detection and treatment of $\mathrm{BOO}$ is essential for sustained graft function [33]. Indeed, adequate long-term graft function is dependent on low-pressure urine storage and effective bladder emptying. In urinary retention, increased intravesical pressure that forms due to contraction of the detrusor muscle adversely affects graft function. This can lead to leakage from the ureterovesical anastomosis or severe infections through the ureteral route, especially in the early period after kidney transplantation. In the long term, intravesical pressure increases due to prolonged detrusor contraction associated with $\mathrm{BOO}$, and this high pressure impairs graft function by causing hydronephrosis. Fortunately, studies including kidney transplant recipients have shown that patients with chronic renal failure due to BPH showed improved renal function in early and late postoperative follow-up [34]. There are both medical and surgical treatment options. Alpha blockers may be useful in patients with mild to moderate LUTSs. It has also been reported that initiating alpha blocker therapy before transplantation in patients diagnosed with $\mathrm{BPH}$ reduces posttransplant LUTSs [35].

For the surgical treatment of BOO, transurethral resection of the prostate (TURP) and transurethral incision of the prostate (TUIP) are proven effective methods. However, identifying these patients before transplantation is a major challenge. It should be known that it is very difficult to predict the incidence of $\mathrm{BOO}$ in these patients due to oliguria or anuria resulting from dialysis [36]. Evaluation of the literature concerning the outcomes of TURP in ESRD patients diagnosed with $\mathrm{BPH}$ prior to transplantation shows that oliguria or anuria increases the risk of postoperative bladder neck obstruction in these patients [37]. For this reason, in patients who are oliguric or anuric and diagnosed with $\mathrm{BPH}$ pretransplantation, it is recommended to perform the operation after transplantation due to the high risk of morbidity [38]. In light of their short- and long-term outcomes, TURP and TUIP also seem to be safe to perform on patients who do not benefit from medical treatment for urinary retention that occurs within the first month after a transplant [39]. A risk of surgery that should be avoided during this period is damage to the ureterovesical anastomosis created during transplantation. Therefore, it is recommended that a cystography be performed preoperatively and that the operation be initiated after confirming that there is no 
anastomotic leak [37]. In addition, low-pressure irrigation and complete hemostasis to prevent clot retention during surgery will reduce postoperative morbidity. Other than this, postoperative bacteremia can be a significant complication after TURP or TUIP. For this reason, if a ureteral catheter is present, the catheter should be removed before TURP and reinserted postoperatively if necessary [37].

TURP is also an effective solution for the surgical treatment of BPH occurring in the long term after transplantation. Recently, TURP was reported to be successful and safe in terms of outcomes at a median follow-up of 42 months in a series of 89 patients who underwent TURP due to $\mathrm{BPH}$ at a median of 13 months posttransplant [34]. In the same study, the authors highlighted the importance of monitoring patients for UTIs in the early postoperative period and for ureteral stenosis in the long term.

TUIP is a TURP alternative especially applicable for the surgical treatment of BOO. Due to the high morbidity rates with TURP, urology guidelines recommend TUIP for small prostate volumes $\left(<30 \mathrm{~cm}^{3}\right)$ and patients at risk of postoperative retrograde ejaculation [6]. However, another recently published study on the surgical management of post-kidney transplant BPH showed that TUIP and TURP were equally safe and effective in alleviating symptoms in men with prostate volumes $<30 \mathrm{~cm}^{3}$ [40].

\section{Allograft Urolithiasis}

Urinary lithiasis following kidney transplantation is a relatively uncommon urological problem seen in 0.17 $1.8 \%$ of the cases [41]. Allograft lithiasis after renal transplantation can either be the result of de novo lithiasis formation or, if stones were present in the donor kidney at the time of transplantation, is called "donor-gifted," in which case the kidney is referred to as a "stone-bearing" kidney. Stones in a transplanted kidney present a risk of obstruction, sepsis, and loss of graft function [42]. Like solitary kidneys, allograft kidneys are a single unit, and any obstacle to urine passage must be addressed immediately. However, the diagnosis and management of allograft lithiasis can be challenging due to the patient's immunosuppressed state, the extra-anatomic location of the transplanted kidney, and renal denervation, and there is little empiric evidence to inform management decisions. Due to these potential problems, lithiasis in the donor kidney has been regarded as a relative contraindication to donation. The 2005 Amsterdam Forum criteria specify that asymptomatic potential donors with a history of a unilateral kidney stone may be suitable candidates if they have no hypercalciuria, hyperuricemia, metabolic acidosis, cystinuria, or hyperoxaluria and the stone is less than $15 \mathrm{~mm}$ in size or potentially removable during transplant [43]. However, recent improvements in both diagnosis and treatment suggest that the subject of stones needs to be revisited.

There are 3 approaches in the management of stones detected in a donor candidate who meets radiological and metabolic criteria. This first approach is clearance of stones from the donor kidney using retrograde intrarenal surgery or extracorporeal shock wave lithotripsy before donor nephrectomy [44]. However, this approach may be problematic as the donor must undergo multiple interventions, the planned transplant date will be delayed, and there will be an increased cost and risk of morbidity. The second approach is a single-stage procedure involving ex vivo ureteroscopy/pyelotomy of the donor kidney immediately after nephrectomy (bench surgery). The stonefree rates of ex vivo stone surgery reported in the literature range between 89.5 and $100 \%[45,46]$. A recently published series of 13 donors with $4-15 \mathrm{~mm}$ stones who underwent ex vivo ureteroscopy $(n=6)$ or ex vivo pyelolithotomy $(n=7)$ further demonstrated the safety and efficacy of both procedures in live donor kidney transplantation [47]. The authors recommended ex vivo ureteroscopy as the first choice because it is easy to perform and has a low risk for morbidity, and they also recommended using a pediatric cystoscope for the procedure because it allows better handling and maneuvering. The third approach is the conservative surveillance of stones $\geq 4 \mathrm{~mm}$. Non-contrast computed tomography has become the gold standard method for visualizing stones in the urinary tract [48]. The higher sensitivity of computed tomography enables the detection of asymptomatic kidney stones $<4 \mathrm{~mm}$ during the preoperative evaluation of potential kidney donors [41]. As a result, the management of stones in this size range has gained importance in recent years. Studies on the spontaneous passage of small ureteral stones $(2-4 \mathrm{~mm})$ in the normal population have reported rates of $87-98 \%[49,50]$. Therefore, active surveillance of stones this size in donor candidates may be an option. In a very recent series of 31 asymptomatic patients with an average stone size of $2.9 \mathrm{~mm}$ who were followed conservatively, it was determined after an average posttransplant follow-up period of 43.1 months that the stone had passed spontaneously in $83.9 \%$ of the patients, become symptomatic within the first year after transplan- 
tation in $9.6 \%$ of the patients, and remained in the kidney at the same size in $6.4 \%$ of the patients [51]. Based on these results, the authors concluded that asymptomatic stones $<4 \mathrm{~mm}$ detected in donors can safely be left in situ.

The management of allograft lithiasis is the same whether it occurs de novo or is donor-gifted. Renal transplant lithiasis is often asymptomatic, which may be due to denervation of the graft $[51,52]$. The most common symptoms associated with posttransplant urolithiasis are unexplained fever, elevated $\mathrm{Cr}$ level, reduced urine output, and hematuria. Some patients may also present with elevated serum $\mathrm{Cr}$, and care must be taken to avoid misinterpreting this finding as a sign of acute rejection. Some patients may also experience lower abdominal pain due to peritoneal irritation related to kidney hydronephrosis.

Options for the management of allograft lithiasis include the conservative approach, extracorporeal shock wave lithotripsy, and endourologic, percutaneous, and open surgical approaches [41]. Minimally invasive approaches such as rigid or flexible ureteroscopic (URS) lithotripsy are currently the most commonly used methods for the treatment of allograft lithiasis. An important factor in the success of URS is the location of the UNC. The position and orientation of the transplanted ureter may be problematic. As ureter implantations to the anterior aspect or dome of the bladder do not leave a suitable anatomic passage posttransplant, it can be difficult to access the ureter and even the renal graft using standard equipment, which can prolong the operative time. The posterolateral extravesical UNC method, also referred to as the modified Lich-Gregoir technique, largely solves this problem. This technique has been observed to substantially facilitate retrograde procedures and shorten the operative time. In a study by Dadkhah et al. [53] comparing 2 UNC techniques, it was reported that the posterolateral extravesical UNC technique can be used to achieve easy and safe access to the upper urinary tract in kidney transplant recipients. In a series presented by Sarier et al. [52], renal pelvic stones were easily removed from 2 pa- tients' transplanted kidneys using the modified Lich-Gregoir technique performed with only rigid URS without the need for flexible URS because a suitable passage to the upper urinary tract was established.

\section{Conclusion}

To summarize the conclusions that can be gleaned from this review, an internal double-J stent should be considered in order to reduce posttransplant urological complications. Conservative follow-up is sufficient for asymptomatic VUR that develops after transplantation in adults. The Sting procedure is an effective treatment solution, especially for low-grade VUR. In the surgical treatment of BOO, TURP and TUIP can be performed safely both in the first month after transplantation and in the long term. Asymptomatic stones $<4 \mathrm{~mm}$ in the donor can be followed up conservatively, and transplantation can be performed with the stone-bearing kidney. For stones $4-15 \mathrm{~mm}$ in size, ex vivo stone surgery is an effective solution. For UNC during transplantation, the modified Lich-Gregoir technique offers a major advantage in endourologic approaches to the treatment of posttransplant allograft lithiasis.

\section{Conflict of Interest Statement}

All authors declare no conflict of interest.

\section{Funding Sources}

No funding was received for this work.

\section{Author Contributions}

M.S., writing-concept; O.Y., data collection; A.Y., analysis; H.T., literature search; and E.K., critical review.

\section{References}

Urological Problems Following Kidney

Transplantation
1 Özkaptan O, Sevinc C, Balaban M, Karadeniz T. Minimally invasive approach for the management of urological complications after renal transplantation: single center experience. Minerva Urol Nefrol. 2018;70(4):422-8.

2 Buttigieg J, Agius-Anastasi A, Sharma A, Halawa A. Early urological complications after kidney transplantation: an overview. World J Transplant. 2018;8(5):142-9.
3 Krajewski W, Dembowski J, Kołodziej A, Małkiewicz B, Tupikowski K, Matuszewski $\mathrm{M}$, et al. Urological complications after renal transplantation: a single centre experience. Cent European J Urol. 2016;69(3):306-11.

4 Bruintjes MHD, d'Ancona FCH, Zhu X, Hoitsma AJ, Warlé MC. An update on early urological complications in kidney transplantation: a National Cohort Study. Ann Transplant. 2019;24:617-24. 
5 Bruintjes MHD, d'Ancona FCH, Zhu X, Hoitsma AJ, Warlé MC. An update on early urological complications in kidney transplantation: a National Cohort Study. Ann Transplant. 2019;24:617-24.

6 Gratzke C, Bachmann A, Descazeaud A, Drake MJ, Madersbacher S, Mamoulakis C, et al. EAU guidelines on the assessment of nonneurogenic male lower urinary tract symptoms including benign prostatic obstruction. Eur Urol. 2015;67(6):1099-109.

7 Mangus RS, Haag BW. Stented versus nonstented extravesical ureteroneocystostomy in renal transplantation: a metaanalysis. Am J Transplant. 2004;4(11):1889-96.

8 Sarier M, Seyman D, Tekin S, Duman I, Uygun B, Demir M, et al. Comparision of ureteral stent colonization between deceased and live donor renal transplant recipients. Transplant Proc. 2017;49(9):2082-5.

9 Fockens MM, Alberts VP, Bemelman FJ, Laguna Pes MP, Idu MM. Internal or external stenting of the ureterovesical anastomosis in renal transplantation. Urol Int. 2016;96(2): 152-6.

10 Yuksel Y, Tekin S, Yuksel D, Duman I, Sarier $\mathrm{M}$, Yucetin L, et al. Optimal timing for removal of the double-J stent after kidney tansplantation. Transplant Proc. 2017;49(3):523-7.

11 Sarier M, Demir M, Duman I, Yuksel Y, Demirbas A. Evaluation of ureteral stent colonization in live-donor renal transplant recipients. Transplant Proc. 2017;49(3):415.

12 Visser IJ, van der Staaij JPT, Muthusamy A, Willicombe M, Lafranca JA, Dor FJMF. Timing of ureteric stent removal and occurrence of urological complications after kidney transplantation: a systematic review and meta-analysis. J Clin Med. 2019;8(5):689.

13 Mano R, Golan S, Holland R, Livne PM, Lifshitz DA. Retrograde endoureterotomy for persistent ureterovesical anastomotic strictures in renal transplant kidneys after failed antegrade balloon dilation. Urology. 2012; 80(2):255-9.

14 Gil-Sousa D, Oliveira-Reis D, Teves F, Príncipe $\mathrm{P}$, Castro-Henriques A, Soares J, et al. Ureteral stenosis after renal transplantation: a single-center 10-year experience. Transplant Proc. 2017;49(4):777-82.

15 Lempinen M, Stenman J, Kyllönen L, Salmela K. Surgical complications following 1,670 consecutive adult renal transplantations: a Single Center Study. Scand J Surg. 2015; 104(4):254-9.

16 Pichler R, Buttazzoni A, Rehder P, Bartsch G, Steiner H, Oswald J. Endoscopic application of dextranomer/hyaluronic acid copolymer in the treatment of vesico-ureteric reflux after renal transplantation. BJU Int. 2011;107(12): 1967-72.

17 Hotta K, Miura M, Wada Y, Fukuzawa N, Iwami D, Sasaki H, et al. Atrophic bladder in long-term dialysis patients increases the risk for urological complications after kidney transplantation. Int J Urol. 2017;24(4):314-9.
18 Salamanca-Bustos JJ, Gomez-Gomez E, Campos-Hernández JP, Carrasco-Valiente J, RuizGarcía J, Márquez-López FJ, et al. Initial experience in the use of novel auto-expandable metal ureteral stent in the treatment of ureter stenosis in kidney transplanted patients. Transplant Proc. 2018;50(2):587-90.

19 Kwong J, Schiefer D, Aboalsamh G, Archambault J, Luke PP, Sener A. Optimal management of distal ureteric strictures following renal transplantation: a systematic review. Transpl Int. 2016;29(5):579-88.

20 Xu G, Li X, He Y, Zhao H, Yang W, Xie Q. Use of self-expanding metallic ureteral stents in the secondary treatment of ureteral stenosis following kidney transplantation. J Endourol. 2015;29(10):1199-203.

21 Nie ZL, Zhang KQ, Li QS, Jin FS, Zhu FQ, Huo WQ. Treatment of urinary fistula after kidney transplantation. Transplant Proc. 2009;41(5):1624-6.

22 Berli JU, Montgomery JR, Segev DL, Ratner LE, Maley WR, Cooper M. Surgical management of early and late ureteral complications after renal transplantation: techniques and outcomes. Clin Transplant. 2015;29(1):2633.

23 Fonio P, Appendino E, Calandri M, Faletti R, Righi D, Gandini G. Treatment of urological complications in more than 1,000 kidney transplantations: the role of interventional radiology. Radiol Med. 2014;120(2):206-12.

24 Sabnis RB, Singh AG, Ganpule AP, Chhabra JS, Tak GR, Shah JH. The development and current status of minimally invasive surgery to manage urological complications after renal transplantation. Indian J Urol. 2016;32(3): 186-91.

25 Latchamsetty KC, Mital D, Jensik S, Coogan CL. Use of collagen injections for vesicoureteral reflux in transplanted kidneys. Transplant Proc. 2003;35(4):1378-80.

26 Mastrosimone S, Pignata G, Maresca MC, Calconi G, Rabassini A, Butini R, et al. Clinical significance of vesicoureteral reflux after kidney transplantation. Clin Nephrol. 1993; 40(1):38-45.

27 Torricelli FCM, Watanabe A, Piovesan AC, David-Neto E, Nahas WC. Urologic issues in pediatric transplant recipients. Transl Androl Urol. 2019;8(2):134-40.

28 Sarier M, Callioglu M, Yuksel Y. The necessity of voiding cystourethrogram for the evaluation of recipient candidates in adult renal transplantation. Russ J Transplant Artif Organs. 2020;22(1):35-9.

29 Balaban M, Özkaptan O. Efficiency and safety of the sting operation on kidney transplanted patients with symptomatic vesicoureteral reflux and neurogenic bladder dysfunction. Transplant Proc. 2020 Jan-Feb;52(1):191-5.

30 Grünberger T, Gnant M, Sautner T, Höbert K, Steininger R, Hofbauer J, et al. Impact of vesicoureteral reflux on graft survival in renal transplantation. Transplant Proc. 1993;25(1 Pt 2):1058-9.
31 Molenaar NM, Minnee RC, Bemelman FJ, Idu MM. Vesicoureteral reflux in kidney transplantation. Prog Transplant. 2017;27(2): 196-9.

32 Gratzke C, Pahde A, Dickmann M, Reich O, Seitz M, Jauch K, et al. Predictive factors for urinary retention following kidney transplantation in male patients. Scand J Urol Nephrol. 2012;46(1):44-7.

33 Gökçe AM, Kaya C, Kara VM, Ozel L, Ruhi C, Titiz MI. Effects of urethral stricture on allografts in kidney transplantation. Transplant Proc. 2015;47(5):1336-9.

34 Sarier M, Tekin S, Duman İ, Yuksel Y, Demir M, Alptekinkaya F, et al. Results of transurethral resection of the prostate in renal transplant recipients: a single center experience. World J Urol. 2018;36(1):99-103.

35 Lubetzky M, Ajaimy M, Kamal L, de Boccardo G, Akalin E, Kayler L. Kidney transplant complications from undiagnosed benign prostatic hypertrophy. Clin Transplant. 2015;29(6): 539-42.

36 Mitsui T, Shimoda N, Morita K, Tanaka H, Moriya K, Nonomura K. Lower urinary tract symptoms and their impact on quality of life after successful renal transplantation. Int $J$ Urol. 2009;16(4):388-92.

37 Sarier M, Duman I, Demir M, Yuksel Y, Emek $\mathrm{M}$, Kukul E. The outcomes of transurethral incision/resection of the prostate (TUIP/ TURP) performed early after renal transplantation. Turk J Urol. 2018;44(2):172-7.

38 Reinberg Y, Bumgardner GL, Aliabadi H. Urological aspects of renal transplantation. J Urol. 1990;143(6):1087-92.

39 Mokos I, Kastelan Z, Basić-Jukić N, Kes P, Pasini J. Transurethral incision/resection of the prostate (TUIP/TURP) in operative treatment of repeated bladder outlet obstruction early after kidney transplantation. Acta Clin Croat. 2011;50(3):381-4.

40 Sarier M, Duman I, Kilic S, Yuksel Y, Demir $\mathrm{M}$, Aslan M, et al. Comparative results of transurethral incision with transurethral resection of the prostate in renal transplant recipients with benign prostate hyperplasia. Urol J. 2018;15(4):209-13.

41 Wong KA, Olsburgh J. Management of stones in renal transplant. Curr Opin Urol. 2013; 23(2):175-9.

42 Verrier C, Bessede T, Hajj P, Aoubid L, Eschwege $\mathrm{P}$, Benoit G. Decrease in and management of urolithiasis after kidney transplantation. J Urol. 2012;187(5):1651-5.

43 Delmonico F; Council of the Transplantation Society. A report of the Amsterdam forum on the care of the live kidney donor: data and medical guidelines. Transplantation. 2005; 79(6 Suppl):S53-66.

44 Ganpule A, Vyas JB, Sheladia C, Mishra S, Ganpule SA, Sabnis RB, et al. Management of urolithiasis in live-related kidney donors. J Endourol. 2013;27(2):245-50. 
45 Olsburgh J, Thomas K, Wong K, Bultitude M, Glass J, Rottenberg G, et al. Incidental renal stones in potential live kidney donors: prevalence, assessment and donation, including role of ex vivo ureteroscopy. BJU Int. 2013; 111(5):784-92.

46 Schade GR, Wolf JS, Faerber GJ. Ex-vivo ureteroscopy at the time of live donor nephrectomy. J Endourol. 2011;25(9):1405-9.

47 Sarier M, Duman I, Yuksel Y, Tekin S, Ozer $M$, Yucetin $L$, et al. Ex vivo stone surgery in donor kidneys at renal transplantation. Int J Urol. 2018;25(10):844-7.
48 Sarier M, Callioglu M, Yuksel Y, Duman E, Emek M, Usta SS. Evaluation of the renal arteries of 2,144 living kidney donors using computed tomography angiography and comparison with intraoperative findings. Urol Int. 2020 May;104(7-8):637-40.

49 Pearce E, Clement KD, Yallappa S, Aboumarzouk OM. Likelihood of distal ureteric calculi to pass spontaneously: systematic review and cumulative analysis of the placebo arm of randomized-controlled trials. Urol Int. 2020 Sep; $1-6$.

50 Coll DM, Varanelli MJ, Smith RC. Relationship of spontaneous passage of ureteral calculi to stone size and location as revealed by unenhanced helical CT. AJR Am J Roentgenol. 2002;178(1):101-3.
51 Sarier M, Duman I, Callioglu M, Soylu A, Tekin S, Turan E, et al. Outcomes of conservative management of asymptomatic live donor kidney stones. Urology. 2018;118:43-6.

52 Sarier M, Duman I, Yuksel Y, Tekin S, Demir M, Arslan F, et al. Results of minimally invasive surgical treatment of allograft lithiasis in live-donor renal transplant recipients: a single-center experience of 3,758 renal transplantations. Urolithiasis. 2019;47(3):273-8.

53 Dadkhah F, Asgari MA, Tara A, Safarinejad MR. Modified ureteroneocystostomy in kidney transplantation to facilitate endoscopic management of subsequent urological complications. Int Urol Nephrol. 2010;42(2):28593. 